\title{
Evolution of laparoscopic liver resection at Singapore General Hospital: a nine-year experience of 195 consecutive resections
}

Brian KP $\underline{G o h}^{1,2}$, MBBS, FRCS, Jin-Yao $\underline{T e o}^{1}$, MBBS, FRCS, Chung-Yip $\underline{\text { Chan }}^{1}$, MBBS, FRCS,

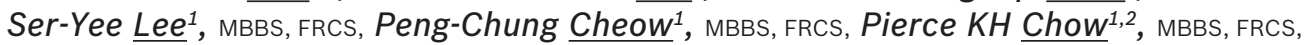
London LPJ $\underline{\mathrm{Ooi}}^{1,2}$, MBBS, FRCS, Alexander YF $\underline{\text { Chung }}^{1,2}$, MBBS, FRCS

INTRODUCTION We aimed to analyse the changing trends, safety and outcomes associated with the adoption of laparoscopic liver resection (LLR) at a single centre.

METHODS A retrospective review of patients who underwent LLR from 2006 to 2014 at our institution was performed. To explore the evolution of LLR, the study was divided into three equal consecutive time periods (Period 1: 2006-2008, Period 2: 2009-2011, and Period 3: 2012-2014).

RESULTS Among 195 patients who underwent LLR, 24 (12.3\%) required open conversions, 68 (34.9\%) had resection of tumours in the difficult posterosuperior segments and $12(6.2 \%)$ underwent major ( $\geq 3$ segments) hepatectomies. Median operation time was 210 (range 40-620) minutes and median postoperative stay was 4 (range 1-26) days. Major postoperative morbidity (> Grade II) occurred in 11 (5.6\%) patients and 90-day/in-hospital mortality was 1 (0.5\%). During the study, the number of LLRs performed showed an increasing trend (Period 1: $n=22 ;$ Period 2: $n=19 ;$ Period 3: $n=154$ ). Other statistically significant trends were: (a) increase in malignant neoplasms resected; (b) increase in resections of difficult posterosuperior segments; (c) longer median operation time; and (d) decrease in open conversion rates.

CONCLUSION Over the study period, the number of LLRs increased rapidly. LLR was increasingly performed for malignant neoplasms and lesions located in the difficult posterosuperior segments, resulting in longer operation times. However, open conversion rates decreased, and there was no change in postoperative morbidity and other perioperative outcomes.

Keywords: hepatectomy, laparoscopic hepatectomy, laparoscopic liver resection, liver resection, minimally invasive

\section{INTRODUCTION}

Since the introduction of laparoscopic surgery in the 1980s, minimally invasive surgery has arguably become the most important and rapid advancement in abdominal surgery over the past two decades. Presently, laparoscopic surgery is the surgical approach of choice for many abdominal operations, including cholecystectomies, ${ }^{(1)}$ appendicectomies, ${ }^{(2)}$ adrenalectomies ${ }^{(3)}$ and colectomies. ${ }^{(4)}$ Numerous randomised controlled trials have consistently demonstrated that laparoscopic surgery is superior to the open approach in terms of decreasing postoperative pain, hospitalisation duration, convalescence time and adhesion formation. ${ }^{(1,4)}$ Laparoscopic liver resection (LLR) was first reported more than two decades ago in 1992 by Gagner et al. ${ }^{(5,6)}$ However, its initial adoption by the surgical community was slow and the first surgical series of LLRs was reported almost ten years later by Cherqui et al in 2000. ${ }^{(7)}$ Subsequently, the number of surgical series on LLR published in the literature has increased exponentially. ${ }^{(8)}$ In 2009, a review by Nguyen et al reported that 127 original articles reporting on 2,804 LLRs were published in the literature. ${ }^{(8)}$ The early widespread adoption of LLR had been largely hindered by the technical complexity of the procedure, which resulted in concerns about the increased risk of bleeding and adequacy of oncologic margins. ${ }^{(6)}$ The first series of LLRs in Singapore was reported by Wang et al in 2009, who described their experience with their first five LLRs. ${ }^{(9)}$ Presently, the procedure has been adopted by most institutions in Singapore.

Over the past decade, LLR has increasingly been practised worldwide, albeit only in high-volume, highly specialised centres, and many investigators have since demonstrated the safety and feasibility of this approach. ${ }^{(8,10)}$ In 2008, an international panel of experts concluded that LLR is safe and effective, with the proviso that it is performed by trained surgeons proficient in both liver and laparoscopic surgery. ${ }^{(10)}$ They further proposed that the laparoscopic approach should be the standard approach for resection of lesions located in the left lateral section (Segments II/III) of the liver. ${ }^{(10)}$ Since the publication of these recommendations, numerous studies have been published demonstrating the safety and feasibility of LLR for major hepatectomies and resection of lesions located in the difficult posterosuperior segments. ${ }^{(11,12)}$ Subsequently, in 2014, the second consensus meeting for LLR was held in Morioka, Japan. Based on the available evidence, the panel of experts at the meeting recommended further expansion of the indications for LLR, including major hepatectomies and resection of tumours in the posterosuperior segments. ${ }^{(13)}$

Despite the recommendations from the two consensus meetings, many liver surgeons remain doubtful and have raised questions about the safety of the widespread adoption of LLR and its reproducibility. ${ }^{(14)}$ It was previously reported by early

${ }^{1}$ Department of Hepatopancreatobiliary and Transplantation Surgery, Singapore General Hospital, ${ }^{2}$ Duke-NUS Medical School, Singapore 
adopters that a surgeon needed to perform around 60 LLR procedures to achieve proficiency and overcome the learning curve. ${ }^{(6,14)}$ During the learning phase, most authors have reported increased open conversion rates, which would negate the benefits of minimally invasive surgery, and some have even reported poorer perioperative outcomes after open conversion. ${ }^{(14-18)}$ The most common reason for open conversion during LLR is bleeding, which is well recognised as an important predictor of postoperative morbidity and mortality after liver resection. ${ }^{(17)}$ Another major concern of LLR, especially when performed by less experienced surgeons, is the possibility of compromised oncologic margins. ${ }^{(16)}$ Nonetheless, it is important to note that more recent studies have demonstrated that the learning curve of LLR can now be shortened. ${ }^{(14,15,19)}$ This has been attributed to recent advancements in laparoscopic equipment as well as improvements in the surgical technique of LLR.

Today, the use of LLR has expanded to include not only major hepatectomies ${ }^{(20,21)}$ but also highly complex surgical procedures, such as resection of Klatskin tumours with bilioenteric anastomoses, ${ }^{(22)}$ combined multiorgan laparoscopic resections, ${ }^{(23,24)}$ living donor major hepatectomies, ${ }^{(25)}$ resection for ruptured tumours ${ }^{(26)}$ and repeat liver resections. ${ }^{(27)}$

In the present study, we report a large single-institution experience of LLR and its evolution since its initial introduction. To the best of our knowledge, this is the largest such experience of LLR from Singapore to date.

\section{METHODS}

All patients who underwent LLR at Singapore General Hospital, Singapore, from January 2006 to December 2014 were identified from a prospectively maintained surgical database. All patient data was obtained retrospectively from clinical, radiological and pathological records. Clinical data was collected from a prospective computerised clinical database (Sunrise Clinical Manager version 5.8 [Eclipsys Corporation, Atlanta, GA, USA]) and patients' clinical charts, whereas operative data was obtained from another prospective computerised database (Oracle Transportation Management 10, IBM, Armonk, NY, USA). In order to study the evolution and changing trends of LLR at our institution over time, we divided the study into three equal time periods, which were defined as Period 1: 2006-2008; Period 2: 2009-2011; and Period 3: 2012-2014.

Relevant perioperative outcomes were recorded, including operation time, blood loss, blood transfusion, postoperative morbidity and postoperative hospitalisation. Various operative techniques were adopted, depending on the individual surgeon's experience and location of the lesion. Our operative technique has been described previously. ${ }^{(13)}$ Postoperative complications were classified according to the Clavien-Dindo grading system, ${ }^{(28)}$ and postoperative mortality was defined as any death within 90 days of surgery or within the same hospitalisation.

In this study, only patients who underwent resection of liver lesions were included. Patients who underwent other laparoscopic liver surgeries, such as hepatic cyst fenestration, drainage of abscess, excision biopsy and local ablation, were excluded. In the present analysis, LLR included pure LLR as well as hand-assisted, robotic-assisted or laparoscopic-assisted liver resection. The fully laparoscopic approach was defined as any procedure that was completed entirely via the conventional laparoscopic approach using multiple ports or a single port. Hand-assisted laparoscopy was defined as any procedure in which the surgeon's hand was inserted into the abdominal cavity, usually using a specialised device such as the Gelport (Applied Medical, Rancho Santa Margarita, CA, USA). Laparoscopic-assisted resection was any procedure in which the preoperative plan was to mobilise the liver via laparoscopy and to complete the resection and parenchymal transection via a small open incision. All procedures that had a preoperative plan of pure laparoscopic resection but had to be completed via open incision were defined as an open conversion regardless of the size of the incision. Conversion from the fully laparoscopic approach to hand-assisted laparoscopy was not considered an open conversion. A close resection margin of less than $1 \mathrm{~mm}$ on histology was considered an $\mathrm{R} 1$ resection.

In general, the patient was placed in the supine position, with or without the legs apart. The operating surgeon stood either between the patient's legs or on the patient's right or left side. For lesions located in the right posterosuperior segments of the liver, the patient was placed in the $45^{\circ}$ or full left lateral position. Intraoperative ultrasonography was routinely performed prior to resection. The liver parenchyma was transected using various devices, including the Harmonic Scalpel (Ethicon Endosurgery, Cincinnati, $\mathrm{OH}, \mathrm{USA})$, Enseal (Ethicon Endosurgery, Cincinnati, $\mathrm{OH}$, USA), LigaSure (Covidien, Boulder, CO, USA), Thunderbeat (Olympus, Tokyo, Japan), Waterjet (Erbe, Tuebingen, Germany) or Cavitron Ultrasonic Surgical Aspirator (Valleylab, Boulder, CO, USA), depending on the individual surgeon's experience or preference. Large pedicles were stapled using endoscopic staplers or clipped. The Pringle manoeuvre was used for selected patients.

All statistical analyses were conducted using IBM SPSS Statistics version 21.0 for Windows (IBM Corp, Armonk, NY, USA). Univariate analysis was performed using Kruskal-Wallis test or chi-square test, as appropriate. All tests were two-sided and $p<0.05$ was considered to be statistically significant.

\section{RESULTS}

During the study period, 195 consecutive patients underwent LLR at our institution. The baseline demographics and outcomes of these patients are summarised in Tables I and II. The median age of the patients was 60 (range 29-86) years and 121 (62.1\%) patients were men. 24 (12.3\%) patients underwent resection for multiple liver nodules. The pathologies of the tumours resected are summarised in Table III. The most common pathology was hepatocellular carcinoma (HCC), which was seen in 102 (52.3\%) patients. $4(2.1 \%)$ resections were performed as emergency procedures for ruptured hepatoma and multiloculated liver abscess. Laparoscopic approaches adopted included fullylaparoscopic liver resection in 177 (90.8\%) patients (including three robotic-assisted procedures), hand-assisted laparoscopy $(n=6)$ and laparoscopic-assisted liver resection $(n=12)$. 
Table I. Baseline demographic and perioperative data of patients who underwent laparoscopic liver resection.

\begin{tabular}{|c|c|c|c|c|c|}
\hline \multirow[t]{2}{*}{ Variable } & \multicolumn{4}{|c|}{ No. (\%)/median (range) } & \multirow[t]{2}{*}{ p-value } \\
\hline & $\begin{array}{c}\text { Period } 1 \\
(n=22)\end{array}$ & $\begin{array}{c}\text { Period } 2 \\
(n=19)\end{array}$ & $\begin{array}{l}\text { Period } 3 \\
(n=154)\end{array}$ & $\begin{array}{c}\text { Total } \\
(\mathrm{n}=195)\end{array}$ & \\
\hline Previous abdominal surgery & $6(27.3)$ & $3(15.8)$ & $47(30.5)$ & $56(28.7)$ & 0.403 \\
\hline Previous liver surgery & $0(0)$ & $0(0)$ & $5(3.2)$ & $5(2.6)$ & 0.505 \\
\hline ASA score & & & & & 0.751 \\
\hline 1 & $2(9.1)$ & $4(21.1)$ & $30(19.5)$ & $36(18.5)$ & \\
\hline II & $17(77.3)$ & $13(68.4)$ & $111(72.1)$ & $141(72.3)$ & \\
\hline III & $3(13.6)$ & $2(10.5)$ & $13(8.4)$ & $18(9.2)$ & \\
\hline Malignant neoplasm & $12(54.5)$ & $16(84.2)$ & $126(81.8)$ & $154(79.0)$ & $0.011^{+}$ \\
\hline Tumour size (mm) & $21(6-150)$ & $25(8-95)$ & $27(6-140)$ & $25(6-150)$ & 0.599 \\
\hline Concomitant surgery & $6(27.3)$ & $6(31.6)$ & $64(41.6)$ & $76(39.0)$ & 0.344 \\
\hline Resection of posterosuperior segment* & $3(13.6)$ & $3(15.8)$ & $62(40.3)$ & $68(34.9)$ & $0.009^{+}$ \\
\hline Histology of background liver cirrhosis & $6(27.3)$ & $7(36.8)$ & $37(24.0)$ & $50(25.6)$ & 0.474 \\
\hline
\end{tabular}

*Defined as Segments I, IVa, VII and VIII. †p < 0.05 was statistically significant. ASA: American Society of Anesthesiologists

Table II. Operative outcomes of patients who underwent laparoscopic liver resection.

\begin{tabular}{|c|c|c|c|c|c|}
\hline \multirow[t]{2}{*}{ Variable } & \multicolumn{4}{|c|}{ No. (\%)/median (range) } & \multirow[t]{2}{*}{ p-value } \\
\hline & $\begin{array}{c}\text { Period } 1 \\
(n=22)\end{array}$ & $\begin{array}{c}\text { Period } 2 \\
(n=19)\end{array}$ & $\begin{array}{l}\text { Period } 3 \\
(n=154)\end{array}$ & $\begin{array}{c}\text { Total } \\
(n=195)\end{array}$ & \\
\hline Operation time (min) & $180(45-400)$ & $200(40-525)$ & $215(45-620)$ & $210(40-620)$ & $0.027^{+}$ \\
\hline Blood loss volume (mL) & $100(0-5,000)$ & $200(0-2,000)$ & $225(0-5,000)$ & $200(0-5,000)$ & 0.122 \\
\hline Intraoperative blood transfusion & $3(13.6)$ & $4(21.1)$ & $25(16.2)$ & $32(16.4)$ & 0.808 \\
\hline Blood transfusion volume $(\mathrm{mL})$ & $0(0-2,300)$ & $0(0-700)$ & $0(0-2,700)$ & $0(0-2,700)$ & 0.857 \\
\hline Pringle manoeuvre & $2(9.1)$ & $1(5.3)$ & $36(23.4)$ & $39(20.0)$ & 0.700 \\
\hline Postoperative stay (day) & $4(1-24)$ & $4(1-12)$ & $4(1-26)$ & $4(1-26)$ & 0.657 \\
\hline Postoperative morbidity & $3(13.6)$ & $5(26.3)$ & $32(20.8)$ & $40(20.5)$ & 0.595 \\
\hline Major morbidity* & $1(4.5)$ & $0(0)$ & $10(6.5)$ & $11(5.6)$ & 0.498 \\
\hline Closest resection margin $(\mathrm{mm})$ & $6.5(0-50)$ & $5(0-60)$ & $6(0-50)$ & $6(0-50)$ & 0.898 \\
\hline
\end{tabular}

*Defined as Clavien-Dindo Grade > II. ${ }^{*} p<0.05$ was statistically significant.

Table III. Pathology of liver tumours resected ( $=195)$.

\begin{tabular}{lc}
\hline Pathology & No. (\%) \\
\hline Malignant & $154(79.0)$ \\
Hepatocellular carcinoma & $102(52.3)$ \\
Liver metastasis & $46(23.6)$ \\
Cholangiocarcinoma/mixed cholangiohepatoma & $5(2.6)$ \\
Other & $1(0.5)$ \\
Benign & $41(21.0)$ \\
Haemangioma & $9(4.6)$ \\
Focal nodular hyperplasia & $7(3.6)$ \\
Cyst & $6(3.1)$ \\
Multiloculated abscess & $4(2.1)$ \\
Adenoma & $3(1.5)$ \\
Angiomyolipoma & $2(1.0)$ \\
Other & $10(5.1)$ \\
\hline
\end{tabular}

The types of LLR, which were categorised based on whether they were minor or major ( $\geq 3$ segments) resections, are summarised in Table IV. 56 (28.7\%) patients had previous abdominal surgery prior to LLR and 5 (2.6\%) patients had previous liver surgery. Repeat liver resections were performed for recurrent HCC $(n=4)$ and colorectal liver metastases $(n=1) .76(39.0 \%)$ patients had synchronous resections, which included colectomy, splenectomy, gastrectomy, porta hepatic lymphadenectomy and cholecystectomies. 68 (34.9\%) patients had resection of posterosuperior liver segments, which were defined as the presence of lesions in Segments I, IVa, VII and VIII. ${ }^{(13)}$ The median operation time was 210 (range 40-620) minutes, and 32 (16.4\%) patients required intraoperative blood transfusions. The median postoperative stay was 4 (range 1-26) days. 3 (1.5\%) patients with malignant tumours had $\mathrm{R} 1$ resections, with close resection margins of less than $1 \mathrm{~mm}$ on pathological investigation.

A total of $24(12.3 \%)$ LLRs required open conversion to complete the procedure. The most common reason for open conversion was bleeding $(n=14)$, which included constant bleeding; 13 patients had slow progress and one patient required emergency conversion for massive bleeding. Another reason for conversion was the extent of the tumour, including additional tumours detected in four patients, poor tumour 
Table IV. Types of laparoscopic liver resections $(\mathbf{n}=195)$.

\begin{tabular}{lc}
\hline Type of resection & No. (\%) \\
\hline Minor resection & $183(93.8)$ \\
1 segment/wedge resection & $100(51.3)$ \\
2 segments & $76(39.0)$ \\
Mixed/multiple segments & $7(3.6)$ \\
Major resection ( $\geq 3$ segments) & $12(6.2)$ \\
3 segments & $1(0.5)$ \\
Right/left hemihepatectomy & $10(5.1)$ \\
Extended hemihepatectomy & $1(0.5)$ \\
\hline
\end{tabular}

localisation in two patients, difficult access/anatomy in two patients, concerns regarding adequate oncologic margins in one patient and adhesions at Calot's triangle during cholecystectomy from cholecystitis in the remaining patient. Conversion from a fully laparoscopic approach to hand-assisted laparoscopy was done for one patient. Overall, 40 (20.5\%) patients experienced postoperative morbidity, among whom 29 (14.9\%) patients experienced minor Clavien-Dindo Grade I or II complications (Table V). Major morbidity (Clavien-Dindo Grades III-V) occurred in $11(5.6 \%)$ patients. This included postoperative mortality in one patient (Clavien-Dindo Grade V) with cirrhosis and HCC, who experienced intraoperative bleeding requiring open conversion. Postoperatively, the patient underwent early reoperation for postoperative bleeding from an anterior abdominal varix, which was successfully controlled. However, this patient subsequently developed liver failure, renal failure and pneumonia, eventually succumbing to sepsis, with multiorgan failure.

Comparison of the baseline demographic and perioperative data of patients who underwent LLR across the three time periods (Tables I and II) showed that LLR was significantly more likely to be performed for malignant lesions (Period 1: 54.5\%; Period 2: $84.2 \%$; Period 3: $81.8 \% ; p=0.011$ ) and was increasingly performed for difficult posterosuperior segments (Period 1: 13.6\%, $\mathrm{n}=3$; Period 2: 15.8\%, $\mathrm{n}=3$; Period 3: 40.3\%, $\mathrm{n}=62 ; \mathrm{p}=0.009$ ). There was no significant difference between the three time periods with regard to the other baseline clinicopathological variables.

Comparison of perioperative and oncological outcomes across the three time periods showed that the median operation time significantly increased over the study period (Period 1: 180 [range 45-400] minutes; Period 2: 200 [range 40-525] minutes; Period 3: 215 [45-620] minutes; $p=0.027$ ), but there was a significant decrease in open conversion rates (Period 1: 22.7\%, $\mathrm{n}=5$; Period 2: 26.3\%, $\mathrm{n}=5$; Period 3: 9.1\%, $\mathrm{n}=14 ; \mathrm{p}=0.028$ ). There was no significant difference between the three time periods with respect to the other perioperative outcomes over time, such as intraoperative blood transfusion rate, median blood loss, postoperative morbidity and length of postoperative stay.

\section{DISCUSSION}

In this study, we noted that the number of LLRs performed at our institution increased exponentially over time, especially during Period 3 (2012-2014). The proportion of LLRs performed increased from less than $5 \%$ to over $25 \%$ of liver resections at
Table V. Postoperative morbidities observed after laparoscopic liver resection according to the Clavien-Dindo grading system $(n=195)$.

\begin{tabular}{|c|c|}
\hline Morbidity & No. \\
\hline Total morbidity* & $40(20.5)$ \\
\hline Minor morbidity (Grades I/II)* & $29(14.9)$ \\
\hline Arrhythmias/atrial fibrillation & 4 \\
\hline Hypertension & 1 \\
\hline Pneumonia & 2 \\
\hline Acute kidney injury & 1 \\
\hline Acute retention of urine & 2 \\
\hline Ileus & 3 \\
\hline Ascites & 3 \\
\hline Delirium & 3 \\
\hline Wound infection & 2 \\
\hline Electrolyte imbalance & 9 \\
\hline Subglottic oedema & 1 \\
\hline Gout flare & 1 \\
\hline Liver decompensation & 1 \\
\hline Neuropraxia & 1 \\
\hline Bile leak (maintenance of surgical drain) & 2 \\
\hline Colorectal anastomosis bleed (bedside tamponade) & 1 \\
\hline Major morbidity (Grades III-V)* & $11(5.6)$ \\
\hline \multicolumn{2}{|l|}{ Grade III } \\
\hline Bleeding requiring reoperation & 3 \\
\hline $\begin{array}{l}\text { Pneumothorax (due to central venous catheter } \\
\text { insertion) requiring chest tube }\end{array}$ & 2 \\
\hline Pleural effusion requiring cope loop insertion & 1 \\
\hline $\begin{array}{l}\text { Upper gastrointestinal bleed from Mallory-Weiss } \\
\text { tear requiring gastroscopy }\end{array}$ & 1 \\
\hline $\begin{array}{l}\text { Infected intra-abdominal collection requiring } \\
\text { percutaneous drainage }\end{array}$ & 2 \\
\hline $\begin{array}{l}\text { Delayed gastric emptying requiring } \\
\text { gastroscopy (simultaneous gastrectomy) }\end{array}$ & 1 \\
\hline \multicolumn{2}{|l|}{ Grade IV } \\
\hline $\begin{array}{l}\text { Acute myocardial infarction requiring intensive } \\
\text { care unit admission }\end{array}$ & 1 \\
\hline \multicolumn{2}{|l|}{ Grade V } \\
\hline $\begin{array}{l}\text { Massive bleeding requiring open conversion and } \\
\text { reoperation, and death due to sepsis }\end{array}$ & 1 \\
\hline
\end{tabular}

Patients may have experienced $>1$ type of morbidity. *Data presented as no. (\%).

our institution during the study period. This rapid increase in case volume could be attributed mainly to the strong desire and initiative of a group of younger surgeons with a keen interest in minimally invasive surgery. Several of these surgeons had returned from training stints abroad, where they learnt about LLR from experienced centres, gaining valuable experience. Over the study period, there was also a significant increase in the proportion of LLRs performed for malignant neoplasms and resection of tumours in the difficult posterosuperior segments. This finding suggests that the indication for LLR at our institution has expanded with increasing case volume and experience. Not surprisingly, there was also a significant increase in the operation times noted, which was associated with the increased frequency of more technically challenging procedures being performed. However, more importantly, and notwithstanding the increase 
in the duration of LLR, there was a decreasing rate of conversion to open surgery and postoperative outcomes remained similar, such as blood loss volume, intraoperative blood transfusion rates, postoperative morbidity and postoperative length of stay.

Despite the rapid rise in the adoption of LLR worldwide, its use remains controversial at present. The main criticisms are related to the technical complexities of the procedure. ${ }^{(10,13,14,16)}$ Critics have questioned its reproducibility and widespread applicability outside of high-volume expert centres, as a relatively long learning curve is reportedly required to achieve technical proficiency. Valid concerns have also been raised about the safety of the procedure, especially during the learning phase and particularly with regard to bleeding and the adequacy of resection margins for tumours. Furthermore, during the initial learning curve, increased conversion rates, especially when they are due to bleeding, could theoretically negate most of the benefits of laparoscopy and may even result in poorer perioperative outcomes. ${ }^{(14,15)}$ Although early adopters reported a learning curve of around 60 procedures, ${ }^{(6)}$ more recent studies have reported that this duration can now be shortened, especially for minor hepatectomies. ${ }^{(14,15)}$ In our recent study, we found that the learning curve for laparoscopic minor hepatectomies was around 20 procedures. ${ }^{(14)}$ This is likely due to the increased standardisation of techniques for LLR and the rapid technological advancements in laparoscopic equipment, such as improved high-definition video systems and better energy devices. Various technical variations have been proposed as alternatives to the pure laparoscopic approach to overcome the technical difficulties of LLR, including laparoscopic assistance, hand-assisted laparoscopy and robotic-assisted laparoscopy..$^{(29,30}$

Recent data from numerous studies has confirmed the oncological safety of LLR. ${ }^{(31,32)}$ The short-term and long-term oncological outcomes of LLR are reported to be equivalent to those of open liver resection for malignant neoplasms, such as HCC and colorectal liver metastases. ${ }^{(31,32)}$ Furthermore, LLR is associated with superior perioperative outcomes, such as decreased postoperative pain, decreased blood loss and decreased hospital stay. ${ }^{(31,32)}$

However, it is important to note that LLR, as recommended by the international expert panel, should only be adopted in centres that have expertise on both liver resection and advanced laparoscopic surgery. ${ }^{(12)}$ Proper training and credentialing are needed to ensure the safe dissemination of LLR. ${ }^{(9)}$ Although many studies have reported on the safety and feasibility of LLR, publication bias is a real concern, as centres with lower case volumes and less successful outcomes may be less likely to report their experience. As with any laparoscopic surgery, conversion to open surgery should generally not be viewed as a complication, but as prudent care for LLR cases. ${ }^{(9)}$ Surgeons attempting LLR should be ready to convert to open procedure for reasons such as lack of case progress or patient safety. ${ }^{(9,16)}$ Ideally, in emergency situations, bleeding should be temporarily controlled via laparoscopic techniques before conversion.

In conclusion, this study demonstrated that LLR is feasible and can be safely adopted. Over the study period, the case volume of LLRs performed increased rapidly at our institution. LLR was performed with increasing frequency for malignant neoplasms and for lesions in the difficult posterosuperior segments, which resulted in longer operation times. However, there was a decrease in the rate of open conversions, and no change in postoperative morbidity and other perioperative outcomes.

\section{REFERENCES}

1. Purkayastha S, Tilney HS, Georgiou P, et al. Laparoscopic cholecystectomy versus mini-laparotomy cholecysectomy: a meta-analysis of randomised control trials. Surg Endosc 2007; 21:1294-300.

2. Goh BK, Chui CH, Yap TL, et al. Is early laparoscopic appendectomy feasible in children with acute appendicitis presenting with an appendiceal mass? A prospective study. J Pediatric Surg 2005; 40:1134-7.

3. Goh BK, Tan YH, Yip SK, Eng PH, Cheng CW. Outcome of patients undergoing laparoscopic adrenalectomy for primary hyperaldosteronism. JSLS 2004; 8:320-5.

4. Law WL, Lee YM, Choi HK, Seto CL, Ho JW. Impact of laparoscopic resection for colorectal cancer on operative outcomes and survival. Ann Surg 2007; 245:1-7.

5. Gagner M, Rheault M, Dubuc J. Laparoscopic partial hepatectomy for liver tumor [abstract]. Surg Endosc 1992; 6:99.

6. Vigano L, Laurent A, Tayar C, et al. The learning curve in laparoscopic liver resection: improved feasibility and reproducibility. Ann Surg 2009; 250:772-82.

7. Cherqui D, Husson E, Hammoud R, et al. Laparoscopic liver resections: a feasibility study in 30 patients. Ann Surg 2000; 232:753-62.

8. Nguyen KT, Gamblin TC, Geller DA. World review of laparoscopic liver resection-2,804 patients. Ann Surg 2009; 250:831-41.

9. Wang E, Kow AW, Chan CY, Liau KH, Ho CK. Starting a laparoscopic hepatectomy programme. Singapore Med J 2009; 50:354-9.

10. Buell JF, Cherqui D, Geller DA, et al; World Consensus Conference on Laparoscopic Surgery. The international position on laparoscopic liver surgery: The Louisville Statement, 2008. Ann Surg 2009; 250:825-30.

11. Nomi T, Fuks D, Kawaguchi $Y$, et al. Learning curve for laparoscopic major hepatectomy. Br J Surg 2015; 102:796-804.

12. Teo JY, Kam JH, Chan $\mathrm{CY}$, et al. Laparoscopic liver resection for posterosuperior and anterolateral lesions-a comparison experience in an Asian centre. Hepatobiliary Surg Nutr 2015; 4:379-90.

13. Wakabayashi G, Cherqui D, Geller DA, et al. Recommendations for laparoscopic liver resection: a report from the second international consensus conference held in Morioka. Ann Surg 2015; 261:619-29.

14. Goh BK, Chan CY, Wong JS, et al. Factors associated with and outcomes of open conversion after laparoscopic minor hepatectomy: initial experience at a single institution. Surg Endosc 2015; 29:2636-42.

15. Cai X, Li Z, Zhang Y, et al. Laparoscopic liver resection and the learning curve: a 14-year, single-center experience. Surg Endosc 2014; 28:1334-41.

16. Troisi RI, Montalti R, Van Limmen JG, et al. Risk factors and management of conversions to an open approach in laparoscopic liver resection: analysis of 265 consecutive cases. HPB (Oxford) 2014; 16:75-82.

17. Costi R, Scatton O, Haddad L, et al. Lessons learned from the first 100 laparoscopic liver resections: not delaying conversion may allow reduced blood loss and operative time. J Laparoendosc Adv Surg Tech A 2012; 22:425-31.

18. Carswell KA, Sagias FG, Murgatroyd B, et al. Laparoscopic versus open left lateral segmentectomy. BMC Surg 2009; 9:14.

19. Liang S, Jayaraman S. Starting a new laparoscopic liver surgery program: initial experience and improved efficiency. Can J Surg 2015; 58:172-6.

20. Ishizawa T, Gumbs AA, Kokudo N, Gayet B. Laparoscopic segmentectomy of the liver: from segment I to VIII. Ann Surg 2012; 256:959-64.

21. Cauchy F, Fuks D, Nomi T, et al. Risk factors and consequences of conversion in laparoscopic major liver resection. Br J Surg 2015; 102:785-95.

22. Lin E, Sarmiento JM. Laparoscopic extended right hepatectomy, portal lymphadenectomy, and hepaticojejunostomy for hilar cholangiocarcinoma. J Laparoendosc Adv Surg Tech A 2014; 24:411-6.

23. Lupinacci RM, Andraus W, De Paiva Haddad LB, Carneiro D' Albuquerque LA, Herman P. Simultaneous laparoscopic resection of primary colorectal cancer and associated liver metastases: a systematic review. Tech Coloproctol 2014; 18:129-35

24. Goh BK, Eng AK. Totally laparoscopic D2 subtotal gastrectomy with hepatectomy and cholecystectomy for gastric neuroendocrine tumor with liver metastases. MIS Case Rep SLS [online] 2014; e00025. Available at: http://crsls.sls.org/201400025/. Accessed October 21, 2017.

25. Brustia R, Komatsu S, Goumard C, et al. From the left to the right: 13-year experience in laparoscopic living donor liver transplantation. Updates Surg 2015; 67:193-200.

26. Goh BK, Lee LS, Chow PK. Early laparoscopic resection of ruptured hepatocellular carcinoma. MIS Case Rep SLS [online] 2013; e00010. Available 
at: http://crsls.sls.org/2013-00010/. Accessed October 21, 2017.

27. Goh BKP, Teo JY, Chan CY, et al. Laparoscopic repeat liver resection for recurrent hepatocellular carcinoma. ANZ J Surg 2017 Oct; 87:E143-6.

28. Dindo D, Demartines N, Clavien PA. Classification of surgical complications: a new proposal with evaluation in a cohort of 6336 patients and results of a survey. Ann Surg 2004; 240:205-13.

29. Hasegawa Y, Koffron AJ, Buell JF, Wakabayashi G. Approaches to laparoscopic liver resection: a meta-analysis of the role of hand-assisted laparoscopic surgery and the hybrid technique. J Hepatobiliary Pancreat Sci 2015; 22:335-41.
30. Kam JH, Goh BK, Chan CY, et al. Robotic hepatectomy: initial experience of a single institution in Singapore. Singapore Med J 2016; 57:209-14.

31. Endo Y, Ohta M, Sasaki A, et al. A comparative study of long-term outcomes after laparoscopy-assisted and open left lateral hepatectomy for hepatocellular carcinoma. Surg Laparosc Endosc Percutan Tech 2009; 19:e171-4.

32. Hasegawa $\mathrm{Y}$, Nitta H, Sasaki A, et al. Long-term outcomes of laparoscopic versus open liver resection for liver metastases from colorectal cancer: a comparative analysis of 168 consecutive cases at a single center. Surgery 2015; 157:1065-72. 